\title{
A EPISTEMOLOGIA DA FORMAÇÃO DE PROFESSORES MATERIALIZADA POR MEIO DOS ORGANISMOS MULTINACIONAIS
}

\section{LA EPISTEMOLOGÍA DE LA FORMACIÓN DE PROFESORES MATERIALIZADA POR MEDIO DE LOS ORGANISMOS MULTINACIONALES}

\author{
THE EPISTEMOLOGY OF TEACHER TRAINING MATERIALIZED BY \\ MULTINATIONAL ORGANISMS
}

\author{
Maria da Conceição dos Santos $\operatorname{COSTA}^{1}$ \\ Michele Borges de SOUZA ${ }^{2}$ \\ Maria da Conceição Rosa CABRAL ${ }^{3}$
}

RESUMO: A Educação na sociedade capitalista tem ganhado cada vez mais centralidade diante dos interesses do capital mediatizados pelas ações dos Organismos Multinacionais para os países (sub) e em desenvolvimento. Este estudo é resultado de uma pesquisa bibliográfica e documental e tem como objetivo apresentar a análise sobre a epistemologia dos Organismos Multinacionais (Banco Mundial e OCDE) para o campo da formação de professores. Os resultados indicam a existência de uma epistemologia do capital cunhada por interesses de ordem burguesa, que advogam políticas públicas que controlam o trabalho docente, cerceiam a autonomia dos professores e promovem processos formativos excludentes e individualizantes, fomentando a alienação e a expansão da precarização nos processos de trabalho.

PALAVRAS-CHAVE: Epistemologia. Organismos multinacionais. Formação de professores. Trabalho docente.

RESUMEN: La Educación en la sociedad capitalista ha ganado cada vez más centralidad frente a los intereses del capital mediatenciados por las acciones de los Organismos Multinacionales para los países (sub) y en desarrollo. Este estudio es el resultado de una investigación bibliográfica y documental y tiene como objetivo presentar el análisis sobre la epistemología de los Organismos Multinacionales (Banco Mundial y OCDE) para el campo de la formación de profesores. Los resultados indican la existencia de una epistemología del capital acuñada por intereses de orden burgués, que abogan políticas públicas que controlan el trabajo docente, cercenan la autonomía de los profesores y promueven procesos formativos excluyentes e individualizantes, fomentando la alienación y la expansión de la precarización en los procesos de trabajo.

\footnotetext{
${ }^{1}$ Universidade Federal do Pará (UFPA), Belém - PA - Brasil. Professora Adjunta do Instituto de Ciências da Educação/Faculdade de Educação Física. ORCID: <https://orcid.org/0000-0002-8256-068X>. E-mail: concita.ufpa@gmail.com

${ }^{2}$ Universidade Federal do Pará (UFPA), Belém - PA - Brasil. Docente da Escola de Aplicação da UFPA. ORCID: <https://orcid.org/0000-0003-4184-0981>. E-mail: michelinhe@yahoo.com.br

${ }^{3}$ Universidade Federal do Pará - (UFPA), Belém - PA - Brasil. Professora Adjunta do Instituto de Ciências da Educação. ORCID: <https://orcid.org/0000-0002-8256-068X>. E-mail: mcrosa@uol.com.br
} 
PALABRAS CLAVE: Epistemología. Organismos multinacionales. Formación de profesores.Ttrabajo docente

ABSTRACT: Education in capitalist society has been increasingly centralized in the interests of capital mediated by the actions of the Multinational Organizations for (sub) and developing countries. This study is the result of a bibliographical and documentary research and aims to present the analysis of the epistemology of Multinational Organizations (OECD and World Bank) to the field of teacher training. The results indicate the existence of an epistemology of capital coined by interests of bourgeois order, which advocate public policies that control the teaching work, restrict the teachers' autonomy and promote excluding and individualizing formative processes, fomenting the alienation and the expansion of the precariousness in the work processes.

KEYWORDS: Epistemology. Multinational organizations. Teacher training. Teaching work.

\section{Introdução}

Este estudo apresenta uma análise sobre a epistemologia produzida pelos Organismos Multinacionais (OM) - Banco Mundial e Organização para a Cooperação e Desenvolvimento Econômico (OCDE) - para o campo da formação de professores e seus possíveis impactos no trabalho docente na educação básica. Sua origem está vinculada às reflexões desenvolvidas, originalmente, na Pesquisa "Trabalho docente em educação física com jovens e adultos trabalhadores na rede municipal de ensino de Belém do Pará".

A temática justifica-se pela necessidade de análise e compreensão do que vem sendo produzido, hegemonicamente, pelos OM para o campo da formação de professores e os desdobramentos para o trabalho docente. Nessa direção, apresenta como questão problema: Qual epistemologia vem sendo materializada pelos Organismos Multinacionais (OM) para o campo da formação de professores e suas possíveis implicações para o trabalho docente na educação básica?

Compreendemos a necessidade histórica e crítica de analisar a "hegemonia discursiva" que se materializa nos documentos oficiais dos OM. Coadunamos com Shiroma, Campos e Garcia (2005) quando afirmam “[...] é fundamental investigar como a ideologia, a lógica e a racionalidade que dão sustentação [...] se articulam com os interesses, valores, perspectivas dos sujeitos que, ao fim e ao cabo, são os que realizam as mudanças (SHIROMA; CAMPOS; GARCIA, 2005, p. 430).

Baseada nos aspectos supracitados, metodologicamente este estudo se inscreve em uma pesquisa bibliográfica e documental, fundamentado na abordagem crítico dialética. 
Gamboa (2012, p. 38-39) destaca que esta abordagem “[...] nos permite conhecer a realidade concreta no seu dinamismo e nas inter-relações [...] e que a tarefa da ciência está orientada para a crítica dos interesses e para a emancipação do homem”. Trouxemos para o diálogo autores e estudiosos do campo da formação de professores, tais como: Brzezinski (2014), Maués, Segenreich e Otranto (2015), e fizemos análise dos seguintes documentos dos OM: a) Professores Excelentes: como melhorar a aprendizagem dos estudantes na América Latina e no Caribe (BRUNS; LUQUE, 2014), organizado pelo Banco Mundial $(\mathrm{BM})$, e b) Professores são importantes: atraindo, desenvolvendo e retendo professores eficazes (OCDE, 2006), organizado pela OCDE.

Este estudo pretende contribuir com a produção do conhecimento sobre os OM e seus desdobramentos para o campo da formação e trabalho docente, aliada à teoria crítica da educação, baseada em um método que nos ajude a ler de forma concreta, histórica e emancipadora a realidade, pois para Gamboa (1998, p. 9):

[...] um método é uma teoria de ciência em ação que implica critérios de cientificidade, concepções de objeto e de sujeito, maneiras de estabelecer essa relação cognitiva e que necessariamente remetem a teorias do conhecimento e a concepções filosóficas do real que dão suporte às diversas abordagens utilizadas nas construções científicas e na produção dos conhecimentos.

A organização do presente artigo está dividida em duas partes. Na primeira parte do texto apresentamos uma síntese da compreensão de como a epistemologia para o campo da formação de professores, concebida pelos OM, coaduna com as ideias de um projeto neoliberal. Na segunda parte, explicitamos como essa epistemologia se materializa na política de formação de professores.

\section{A Epistemologia dos Organismos Multinacionais para o campo da Formação de Professores}

A crise estrutural do capitalismo vem atingindo estruturas e poderes institucionais, demarcando consequências nas relações da força de trabalho, "[...] relações sociais, políticas de bem-estar social, arranjos tecnológicos, modos de vida, pertencimento à terra, hábitos afetivos, modos de pensar e outros mais" (HARVEY, 2007, p. 3).

O campo da formação de professores recebe atenção social, cultural, econômica e política, pois atua em interface com o campo do trabalho na sociedade capitalista, tendo em 
vista a educação ser um campo nevrálgico para as determinações do atual sistema. E o Estado passa a ser um relevante canal da materialidade das políticas e práticas neoliberais, com o objetivo de ajustar as estruturas sociais para as políticas e práticas neoliberais (HARVEY, 2007).

Isto pode ser claramente visualizado nas políticas educacionais que passaram a vigorar a partir da década de 1990 no Brasil, e que trouxeram consigo a prerrogativa de um projeto societário neoliberal, cujas premissas foram ao encontro de estratégias de legitimação para obtenção de um consenso na área educacional que viabilizasse a concretização, a consolidação, a manutenção e a reprodução dessa ideologia. Cumpria-se uma dupla determinação: aumentar a produtividade do trabalho cada vez mais racionalizado e materializar o novo padrão de sociabilidade neoliberal na escola (NEVES, 2013), daí que se passou a focar com maior intensidade na formação e no trabalho dos professores da Educação Básica.

Nesta nova maneira de se pensar a educação no país, a partir das reformas implantadas nos anos de 1990, o papel do professor passa a ser central, pois ele figura como formulador e disseminador da hegemonia burguesa na sociedade capitalista e assume lugar de destaque na agenda dos $\mathrm{OM}$ e dos governos brasileiros, constituindo-se como o principal intelectual orgânico da nova Pedagogia da Hegemonia. A educação escolar tornase fundamental para a manutenção da hegemonia capitalista, servindo de maneira direta à burguesia (NEVES; SANT’ANNA, 2005).

Nessa direção, há a necessidade de compreender que epistemologia está por trás das políticas dos OM para o campo da formação de professores e assinalar algumas implicações para o trabalho docente. De acordo com Gamboa (1998, p. 11):

O termo "epistemologia" que literalmente significa Teoria da Ciência (Wissenschaftstheorie), foi criada recentemente e com uma definição já comprometida com a tradição positivista, na medida em que conota a redução da Teoria do Conhecimento (Erkenntnistheorie) à Teoria do Conhecimento Científico. Segundo Habermas, após Kant, a Teoria do Conhecimento (Gnoseologia) foi desaparecendo, com a ruptura das relações entre a Filosofia e a ciência.

Não temos a intenção neste estudo de abordar as abordagens epistemológicas (empírico-analítica, fenomenológica-hermenêutica e crítico-dialética, dentre outras) que Gamboa $(1998 ; 2012)$ aprofunda em seus estudos, mas partimos de uma tese de que há 
uma epistemologia do capital fomentada pelos OM para a implementação de políticas no campo da formação de professores para os países (sub) e desenvolvidos.

Uma epistemologia do capital, que advoga políticas públicas que controlam o trabalho docente, cerceia a autonomia docente, mediante processos formativos excludentes e individualizantes, que fomentam o trabalho alienado, causando a desefetivação dos(as) trabalhadores(as) da educação. Advogamos que a teoria da ciência (GAMBOA, 1998) evidenciada para o campo da formação de professores pelos OM coaduna com o processo de reestruturação produtiva, logrando a manutenção do status quo.

De acordo com Maués, Segenreich e Otranto (2015), alguns Organismos Multinacionais operam reconhecendo que a educação desempenha um importante papel no processo de saída da crise estrutural do capital. Para as autoras,

\begin{abstract}
A formação de professores ganhou, nos últimos 20 anos, um status de prioridade. Os índices de escolarização e de aprovação passaram a ser os motivos centrais para que os governos, nas diferentes esferas federativas, passassem a ter uma forte preocupação com a formação, na medida em que imputavam ao professor a responsabilidade pelo processo de ensino e aprendizagem. Ademais, com a implantação de políticas de avaliação, a partir dos anos 1990, se instalou uma política de responsabilização dos professores pelos resultados que os alunos obtêm nos exames externos e padronizados (MAUÉS; SEGENREICH; OTRANTO, 2015, p. 47).
\end{abstract}

Os aspectos destacados acima traduzem a centralidade que o campo da formação de professores vem ganhando nos últimos anos, a preocupação em torno deste campo, com vistas ao processo de responsabilização docente dos desafios e fragilidades em que se encontra o campo educacional dos países (sub) e desenvolvidos.

As análises dos documentos eleitos para o presente texto, apresentadas a seguir, irão aprofundar a temática deste estudo.

\title{
A lógica do professor excelente como instrumento para uma política de formação de professores
}

A formação de professores na concepção sócio-histórica é um processo que começa com a formação inicial e acompanha o docente ao longo de sua vida profissional,

marcado pela complexidade do conhecimento, pela reflexão, pela criatividade, pela ação, pela crítica, pelo reconhecimento da identidade cultural dos envolvidos nos processos formativos e pelas relações instauradas entre formadores e discentes (BRZEZINSKI, 2014, p. 116). 
A outra concepção de formação se apoia em um projeto neoliberal, que encara a educação como mercadoria e na qual seus protagonistas se submetem às diretivas dos Organismos Multinacionais, como a qualidade total, que descarta o conhecimento como base fundamental da formação docente, com as competências operativas, que coloca o trabalho voltado para a execução, sem exigências de qualificação científica, subremunerado e submetido à precarização e à exploração do trabalho (BRZEZINSKI, 2014). É uma visão de mundo, de sociedade, de educação subsumida ao capital e regida pelas leis de mercado, afirma Brzezinski (2014).

O BM e a OCDE colocam a formação de professores como importante para a melhoria da qualidade da educação, contudo centralizam toda a responsabilidade no professor, desconsiderando outros fatores, tais como condições de trabalho, salários, falta do plano de carreira etc. Estes OM não levam em consideração a realidade concreta em que se encontra a escola pública brasileira e dos demais países da América Latina e Caribe, incluindo o trabalho docente que está em um processo de desqualificação, de precarização e de exploração, assim como não consideram as condições materiais dos educandos, sua organização familiar, ou desorganização, características culturais etc., palco de enfrentamento cotidiano dessa categoria.

\begin{abstract}
Essa "obrigação de resultados" que hoje é imposta ao professor não leva em conta, na maioria das vezes, as questões estruturais e conjunturais que envolvem a profissão, tais como condições de trabalho, o que implica em turmas com mais de 50 alunos; falta de uma política de valorização do magistério, o que inclui plano de cargos e salários e um plano de formação continuada; formas de contratação temporária; uma política previdenciária que permita ao docente se aposentar com dignidade, dentre outras questões fundamentais que deixam de ser consideradas nessas regulações que incidem sobre o trabalho docente, precarizando-o e flexibilizando-o (MAUÉS, 2008, p. 10).
\end{abstract}

Há um interesse político, social e econômico dos governos federal, estadual e municipal em promover, fomentar e gerir recursos para formação e capacitação de professores em serviço. No âmbito da reestruturação produtiva e da busca por competitividade, a mídia foi responsável por alastrar, e tonar consensual, o slogan da qualidade, advinda das reformas educacionais na América Latina e Caribe "sobre o imperativo de se melhorar os indicadores educacionais, visando apoiar a criação de parâmetros e avaliações para os vários níveis e modalidades de ensino" (SHIROMA; SCHNEIDER, 2013, p. 90-91). Avaliar o desempenho do professor tornou-se primordial para melhorar os índices educacionais no país, na ótica dos reformadores da educação. 
Para tanto, imputaram às reformas educativas a lógica da avaliação do desempenho docente entendida

como um mecanismo promotor de racionalização de custos e recursos docentes e como uma política cujos resultados afetariam o desenho dos currículos e programas de formação inicial e contínua de professores, no sentido de adequá-los aos padrões de competência esperados dos docentes (SHIROMA; SCHNEIDER, 2013, p.92).

No documento do BM Achieving world class education in Brazil: the next agenda (BRUNS; EVANS; LUQUE, 2010), há uma clara evidência da responsabilização dos docentes perante os resultados educacionais. Neste caso, o BM visualiza como a política educacional poderá recrutar (bons) professores e melhorar o desempenho daqueles que estão em serviço. A proposta que está implícita é de "atingir e remodelar a formação via avaliação desde o início da carreira" (SHIROMA; SCHNEIDER, 2013, p.92). Para tanto, haveria necessidade de uma reformulação na trajetória da carreira docente com base em três elementos: atrair pessoas de alto nível; apoiar a melhoria contínua na prática; recompensar o desempenho (BRUNS; EVANS; LUQUE, 2010). Nessa perspectiva, a urgência em reformar as políticas de formação de professores na América Latina e no Caribe é condensada no documento "Professores Excelentes: como melhorar a aprendizagem dos estudantes na América Latina e no Caribe" (BRUNS; LUQUE, 2014). Organizado pelo Banco Mundial, este documento pauta “[...] a qualidade da educação no centro da agenda política [...]" (p. 2), condicionando-a à qualidade dos professores, propondo processos de recrutamento aos jovens "talentosos" para a docência, com vista ao “[...] aumento da eficácia dos professores em serviço e o provimento de incentivos que motivem os professores ao máximo esforço em todas as salas de aula, todos os dias, com todos os alunos" (BRUNS; LUQUE, 2014, p. 2)

No ano de 2006 a OCDE fez um estudo intitulado "Professores são importantes: atraindo, desenvolvendo e retendo professores eficazes" (OCDE, 2006) em que evidencia que a educação é o fator que contribui para o crescimento econômico do país - com produção de mão-de-obra - e analisa o papel dos professores no processo de ensinoaprendizagem demonstrando que a questão docente é prioritária e está no centro das reformas educacionais em curso, além de ser o elemento chave para melhorar a qualidade da educação (FERREIRA, 2011). Os resultados do referido estudo apresentam a realidade que cerca os países e são comuns a todos, pois retrata a dificuldade em atrair professores qualificados. Deste modo, a OCDE recomenda que as políticas devam orientar-se de 
maneira a melhorar o status da docência, tornar a carreira da profissão competitiva no mercado de trabalho, melhorar as condições do ambiente em que o professor desenvolve seu trabalho, ampliar as fontes de suprimento de professores (FERREIRA, 2011). Além disso, a OCDE orienta que se deve atrair e reter tipos de professores específicos, apenas os mais eficazes, a mesma orientação dos documentos do Banco Mundial de 2010 e 2014. Contudo, Ferreira (2011) aponta que existem duas grandes preocupações da OCDE, são elas: a escassez quantitativa de professores e os aspectos qualitativos que compõem "a força de trabalho docente em termos de background acadêmico, gênero, conhecimentos e habilidades" (OCDE, 2006, p. 39).

O que podemos afirmar, tomando como referência a pesquisa da OCDE (2006) e a mais recente do BM $(2010 ; 2014)$, é que o governo brasileiro vem desenvolvendo políticas públicas educacionais nos moldes das orientações do BM para carreira docente - tida como não atrativa -, e uma consequência disso é que a formação em serviço tornou-se o epicentro da reforma política da formação de professores.

A determinação para o campo do trabalho docente é acurada pela "[...] capacidade dos professores de assegurar que seus alunos aprendam é condição sine qua non para que alunos e países colham os benefícios econômicos e sociais da Educação" (BRUNS; LUQUE, 2014, p. 6). Isso, sem levar em consideração os processos que envolvem: condições de trabalho - infraestrutura, materiais pedagógicos, equipamentos; a remuneração, formas de contratação, a jornada de trabalho -; quantidade de alunos(as) em sala; processos formativos permanentes que subsidiam os/as trabalhadores/as da educação para a realização do trabalho, dentre outras mediações que interferem no trabalho e subjetividade docente.

A epistemologia para o campo da formação é forjada pela determinação burguesa, com desdobramentos para o campo do trabalho, que aliena e controla, precariza os processos de trabalho, sem levar em consideração as mediações necessárias supracitadas para a sobrevivência objetiva e subjetiva dos(as) trabalhadores(as) da educação, ocasionando a competição, a meritocracia docente, o adoecimento docente em detrimento do slogan do bom professor e aprendizagem dos(as) alunos(as) propalada como fatores determinantes para potencializar os benefícios econômicos para o setor educacional.

Há um processo de revitalização da teoria do capital humano que se concretiza na epistemologia do capital materializada nos ordenamentos dos OM para as políticas de formação de professores. A afirmativa sobre o entendimento de que "[...] a forma como o capital humano contribui para o crescimento econômico [...]" aponta para a educação como

RIAEE - Revista Ibero-Americana de Estudos em Educação, Araraquara, v. esp, n. 3, p. 2041-2053, dez., 2018. E-ISSN: $1982-5587$. 
responsável pelos índices tanto educacionais quanto econômicos nos países da América Latina e Caribe.

Para Frigotto (2010), os nexos entre educação e desenvolvimento, educação e trabalho, capital e trabalho, são mascarados pela teoria do capital humano, pois o que está por trás dessa lógica é o processo de exploração das relações e processos sociais, tanto do trabalho quanto da formação, para a manutenção dos ditames e controle ideológico da educação, formação e por extensão o campo do trabalho.

No capitalismo, a forma dominante que assume o trabalho é de emprego, ou seja, da compra e venda da força física, psíquica e intelectual daqueles que são desprovidos da propriedade dos meios e instrumentos de produção. Uma mercadoria especial que os proprietários dos meios e instrumentos de produção compram e gerenciam de tal sorte que o dispêndio da mesma pelo trabalhador no processo produtivo pague o seu valor de mercado em forma de salário ou meios de subsistência e, além disso, produza um valor excedente ou mais-valia que é apropriado pelo comprador. O capital apropria-se privadamente também da ciência e tecnologia e as incorpora ao processo produtivo como trabalho vivo objetivado e que se tornam uma força contra o trabalhador e meio de ampliar o lucro mediante a sua superexploração (FRIGOTTO, 2010, p. $3)$.

Os aspectos apontados por Frigotto (2010) sobre o campo do trabalho são categorizados com base nos seguintes elementos preconizados no documento do Banco Mundial: a) controle sobre o trabalho do professor entre o tempo destinado para a realização de tarefas e aprendizagem dos alunos; b) necessidade clara sobre o controle e gestão do tempo de instrução realizados em sala de aula, estimulando a criação de parâmetros para o desempenho dos professores entre uma sala de aula e outra; c) determinação sobre observação direta do trabalho docente nas salas de aulas dentro da escola, apontando como responsabilidade desta ação os diretores das escolas, estabelecendo modelos eficazes que possam servir de exemplos para a formação de professores, dentre outros (BRUNS; LUQUE, 2014).

Tais elementos devem coadunar com o processo de recrutamento de professores, que pautem em níveis competitivos a partir de três mecanismos: “- Aumento dos padrões para ingresso na formação de professores; - Aumento da qualidade das escolas de formação de professores e aumento dos padrões para a contratação de novos professores" (BRUNS; LUQUE, 2014, p.25). O conjunto de mecanismos afirma que a autonomia universitária é um obstáculo para a materialização das mudanças nos processos de formação de professores, que há a necessidade de garantir instrumentos para a política de 
contratação de novos professores, a partir dos instrumentos: a) padrões nacionais para professores; b) testes pré-emprego das competências de professores; e c) certificação alternativa (BRUNS; LUQUE, 2014, p. 28)

A lógica é reformar a política de formação de professores dos países da América Latina e Caribe e controlar o trabalho docente mediante os aspectos essenciais de:

Indução: apoio ao desenvolvimento dos professores durante os primeiros cinco anos mais críticos de magistério; Avaliação: sistemas para a avaliação regular dos pontos fortes e fracos de cada professor; Desenvolvimento profissional: treinamento eficaz para corrigir os pontos fracos identificados dos professores e alavancar as competências dos atores de melhor desempenho; Gestão: adequar as atribuições dos professores às necessidades das escolas e dos alunos e criar escolas eficazes por meio de práticas compartilhadas e interação profissional (BRUNS; LUQUE, 2014, p. 34).

Em tempo, também, contribuir com a desmobilização política dos professores junto aos sindicatos e movimentos que lutam pela classe trabalhadora docente, pois para o Banco Mundial os sindicatos dos professores são considerados poderosos e representam um impeditivo das "reformas consideradas uma ameaça a seus interesses" (BRUNS; LUQUE, 2014, p. 48).

\section{Considerações finais}

Após analisar os documentos do Banco Mundial e da OCED, tendo como referência autores do campo da formação de professores já referidos, retomamos aqui a questão que orientou a elaboração do presente texto - a epistemologia materializada pelos Organismos Multinacionais (OM) para o campo da formação de professores e possíveis implicações para o trabalho docente -, para tecer algumas considerações.

A formação em serviço tornou-se o epicentro da reforma política da formação de professores, no Brasil, consequência do desenvolvimento, por parte do governo brasileiro, de políticas públicas educacionais nos moldes das orientações do Banco Mundial. A exemplo de políticas educacionais dos anos 1990 no Brasil, que buscava aumentar a produtividade do trabalho cada vez mais racionalizado e materializar o novo padrão de sociabilidade neoliberal na escola (NEVES, 2013), a atenção recebida pelo campo de formação de professores - que faz interface com o campo trabalho na sociedade capitalista 
- é uma forma de materializar políticas e práticas neoliberais por parte dos OM. O estudo da OCDE (2006) sinaliza tal interpretação, ao indicar que a educação é o fator que contribui para o crescimento econômico do país, com produção de mão-de-obra. O documento recomenda, entre outros, melhorar o status da docência, tornar a carreira da profissão competitiva no mercado de trabalho (FERREIRA, 2011). Assim como o documento do Banco Mundial (2010; 2014), a OCDE orienta que se deve atrair e reter apenas os professores mais eficazes.

A lógica que dá sustentação às "teses" propugnadas nos documentos analisados se articulam com os interesses e valores fundamentados em uma concepção de educação como mercadoria.

Tanto o Banco Mundial como a OCDE vinculam a formação de professores à melhoria da qualidade da educação, centralizando a responsabilidade pelo processo no professor, desconsiderando fatores como condições de trabalho docente, condições materiais e características culturais dos educandos e a realidade concreta em que se encontra a escola pública brasileira e dos demais países da América Latina e Caribe.

Nos documentos analisados, os professores são responsabilizados pelos processos educativos e por todas as demandas que os afetam tanto na formação quanto no trabalho docente. Além da responsabilização de "professores excelentes" ser vinculada ao desenvolvimento econômico dos países da América Latina e Caribe, soma-se o peso de ser professor, integrante da classe dos trabalhadores da educação.

Por fim, importante ressaltar que o BM identifica dois obstáculos para a materialização das mudanças nos processos de formação de professores: os sindicatos dos professores, considerados poderosos e representam um impeditivo das "reformas"; e a autonomia universitária. Felizmente, esse reconhecimento sinaliza, de alguma forma, um ponto a favor da formação e trabalho como direitos inalienáveis dos sujeitos docentes.

\section{REFERÊNCIAS}

BRUNS, B.; EVANS, D.; LUQUE, J. Achieving World-Class Education in Brazil: the next agenda. World Bank Publications, 2010. Disponível em: http://web.worldbank.org. Acesso em: 10 jul. 2017.

BRUNS, B.; LUQUE, J. Professores Excelentes: Como melhorar a aprendizagem dos estudantes na América Latina e no Caribe. Grupo Banco Mundial, Washington, D.C, 2014.

BRZEZINSKI, I. Formação de profissionais da educação e mudanças da LDB/1996: dilemas e desafios? Contradições e compromissos. In: BRZEZINSKI, Iria (Orgs.) 
LDB/1996 contemporânea: contradições, tensões, compromissos. São Paulo: Cortes, 2014.

FERREIRA, D. L. A organização para cooperação e desenvolvimento econômico (OCDE) e a política de formação docente no Brasil. 2011. 330 f. Belém, Tese (Doutorado) - Universidade Federal do Pará, Instituto de Ciências da Educação, Programa de Pós-Graduação em Educação. Belém, 2011.

FRIGOTTO, G. Trabalho. In: OLIVEIRA, D. A.; DUARTE, A. M. C.; VIEIRA, L. M. F. DICIONÁRIO: trabalho, profissão e condição docente. Belo Horizonte:

UFMG/Faculdade de Educação, 2010. CDROM.

GAMBOA, S. S. Epistemologia da Pesquisa em educação. 1998. 156f. Tese (Doutorado em Educação), Faculdade de Educação, Unicamp, 1998.

GAMBOA, Silvio S. Pesquisa em educação: métodos e epistemologias. 2. ed. Chapecó: Argos, 2012.

HARVEY, D. Neoliberalismo como destruição criativa. Revista InterfacEHS, v. 2, n. 4, Tradução, ago., 2007.

MAUÉS, O. C. A Política de Educação Superior para a Formação e o Trabalho Docente: A Nova Regulação Educacional. In: REUNIÃO ANUAL DA ASSOCIAÇÃO NACIONAL DE PÓS-GRADUAÇÃO E PESQUISA EM EDUCAÇÃO - ANPED, 31ª . 2008, Caxambu. Anais... Rio de Janeiro: ANPED, p. 1-18. Disponível em:

http://www.anped.org.br/sites/default/files/gt11-3974-int.pdf. Acesso em: 02 fev. 2018.

MAUÉS, O.; SEGENREICH, S.; OTRANTO, C. As políticas de formação de professores: a expansão comprometida. Revista Educação em Questão. Natal, v. 51, n. 37, p. 42-72, jan./abr., 2015.

NEVES, L. M. W. O professor como intelectual estratégico na disseminação da nova pedagogia da hegemonia. In: REUNIÃO ANUAL DA ASSOCIAÇÃO NACIONAL DE PÓS-GRADUAÇÃO E PESQUISA EM EDUCAÇÃO - ANPED, 36a , 2013. Anais... Goiânia-GO: ANPED, p.1-15. Disponível em:

http://36reuniao.anped.org.br/pdfs_trabalhos_encomendados/gt05_trabencomendado_lucia neves.pdf. Acesso em: 02 fev. 2018.

NEVES, L. M. W. SANT'ANNA, R. Introdução: Gramsci, o Estado educador e a nova Pedagogia da hegemonia. In: NEVES, Lúcia Maria Wanderley. A nova pedagogia da hegemonia: estratégias do capital para educar o consenso. SP: Xamã, 2005.

OCDE. ORGANIZAÇÃO PARA COOPERAÇÃO E DESENVOLVIMENTO ECONÔMICO. Professores são importantes. Atraindo, desenvolvendo e retendo professores eficazes. São Paulo: Coedição Moderna: OCDE, 2006.

SHIROMA, E.; SCHNEIDER, M. C. Avaliação de desempenho docente: contradições da política "para poucos” na era do "para todos”. Inter-Ação, Goiânia, v. 38, n. 1, p. 89-107, jan./abr., 2013. 
SHIROMA, E. O.; CAMPOS, R.F.; GARCIA, R. M. C. Decifrar textos para compreender a política: subsídios teórico-metodológicos para análise de documentos. PERSPECTIVA, Florianópolis, v. 23, n. 2, p. 427-446, jul./dez., 2005.

\section{Como referenciar este artigo}

COSTA, Maria da Conceição dos Santos.; SOUZA, Michele Borges de.; CABRAL, Maria da Conceição Rosa. A Epistemologia da formação de professores materializada por meio dos Organismos Multinacionais. Revista Ibero-Americana de Estudos em Educação, Araraquara, v. esp, n. 3, p. 2041-2053, dez., 2018. E-ISSN: 1982-5587. DOI: 10.21723/riaee.unesp.v13.iesp3.dez.2018.11142.

Submetido em: 28/02/2018

Revisões requeridas: $10 / 04 / 2018$

Aprovado em: 20/07/2018 